\title{
Potential Barriers in Management of Refurbishment Projects
}

\author{
Faisal Arain \\ faisal.arain@,nus.edu.sg \\ Department of Building, School of Design and Environment, National University of Singapore \\ Singapore
}

\begin{abstract}
:
The study presents the sources of the barriers in management of refurbishment projects that may cause delays and escalate costs. To achieve the study objectives, the information was acquired through personal interviews and in-depth discussions with the architects and contractors of the seven refurbishment projects selected in eastern province of Saudi Arabia. It addresses issues often overlooked by the management team in a refurbishment project during the design, document preparation, and construction stages. The twelve most important sources of barriers were the degradation of undamaged materials over time, formidable variations to original structure, salvaged materials, conflict between responsibilities and liabilities, missing design information, illogical imposed conditions, selecting contract types, improper site survey, concurrent operation by owners, selection of contractor, escalated costs and delays during refurbishment, and underpayment for architect's services were revealed from the in-depth interviews and discussion with the architects and the contractors of the refurbishment projects. Reasons for these problems of management are reviewed with emphasis on the role of the architect in avoiding underestimation of required work during the stages of the project. Recommendations are given to minimize ambiguities in the scope of the work and avoid disputes among the parties to the contract. This can be achieved by employing an experienced architect and by making sound prompt decisions through out the project lifecycle.
\end{abstract}

\section{INTRODUCTION}

Refurbishment projects are emerging in Saudi Arabia [1]. The evolution of living standards in have generated many manufacturing and building employment opportunities The growth of towns in has accelerated as a result of high population growth. Large and complex projects have been built, attracting consultants and contractors from all over the world. Most of these parties appear to lack a sufficient understanding of the social, cultural and physical environment of Saudi Arabia. This situation, coupled with inexperienced owners, has led to inadequate designs resulting in many changes to plans, specifications, and contract terms [1]. Success in completing building projects depends mainly on proper coordination, cooperation, and communication among construction parties. These construction parties involve owners, architects, construction contractors, subcontractors, and maintenance contractors [2].

Refurbishment projects are increasing worldwide because of current economic conditions and resulting budget cuts.
Clancy [3] estimated that refurbishment contracts starting in the United Kingdom in 1995 would amount to 7 billions US dollars, which is equivalent to $25 \%$ of all construction orders for the year. In addition to the economic factors, damaged buildings due to terror attacks may be the source of considerable repair and refurbishment work, particularly for many Middle Eastern countries [4][5].

The construction process is influenced by highly changing variables and unpredictable factors that could result from different sources. These sources include the performance of construction parties, resource availability, environmental conditions, involvement of other parties and contractual relations. As a consequence of these sources, the construction of project may face problems which could cause delay in the project completion time [6]. In many cases, the decision to refurbish a building is made with little information about the special nature of such a project. Refurbishment projects are frequently characterized by taking more time and costing more money than estimated during the design stage. This can be the source of serious litigation among the project owner, the architect or the contractor.

A construction project traditionally involves two major professionals in the construction industry. These two professionals are the architect and the contractor. Communication for the effective coordination between these two parties is the key factor to be considered for the successful completion of a project. It is postulated that disagreements between these two parties have caused barriers in the design phase and construction process. Mendelsohn [7] observed that probably $75 \%$ of the problems encountered on site were generated at the design phase. This is not to say that contractors do not create a slew of problems of their own but that these problems were often compounded by inherent design flaws. If one were to seriously consider ways to reduce problems on site, an obvious place to begin with is to focus on what the project team can do to eliminate these problems at the design phase.

The problems in refurbishment projects may originate from design decisions made in good faith by the architect. The process of making decisions in a design office depends very much on the experience of the designers involved [8]. Unfortunately, many refurbishment projects are not adequately documented, so that experience gained on one project is not available to the architect who is beginning a new project. Focusing on interfaces, Fredrickson [9] noted that each project, client and designconstruct delivery team has unique design needs. There is 
no "one size fits all" way of identifying the right design approach to a particular project. However, the guidelines adopted from previous projects can help to assist a project delivery team to determine how the design should be handled that can greatly improve the project's chances of success. In a survey done by Daoud [10], it was found that the majority of the design offices did not consciously collect feedback from the site staff, designers, and clients of their completed projects.

Assaf, et al. [11] reported that for new building designs one in every five projects suffered from poor quality of documents, resulting in construction problems. Four out of five refurbishment projects suffered from the same problem. Their interpretation for this was that refurbishment work was disadvantaged by being treated too much like new work. Information about what existed on the site tended to be neglected in favor of descriptions of the proposed work, and the relationship between the new and the existing building was often unclear, requiring more detailed information than was supplied. Mendelsohn [7] suggested that an architect has a conceptual mind and a constructor has a concrete mind. One relates to intangibles and the other relates to tangibles.

Problems in refurbishment work may also originate during the bidding stage, including negotiations with the successful bidder, and the selection of the contractor. Serious difficulties may arise during the construction period if it is overlooked that in many cases the work in refurbishment projects is formed out of sequence. In this study refurbishment is seen as an option at the end of the service life of a building. The end of service life occurs when the building fails to perform as required in its use. This failure can be a result of three causes: failure resulting from change(s) in performance (deterioration based on failure); failure resulting from change(s) in requirements (obsolescence based failure); failure resulting from change(s) in use. Definitions of the central terms are given in Appendix 1.

The objectives of this paper are to present the sources of the problems in refurbishment work that cause delays and escalate costs, and to propose guidelines to resolve these problems. It addresses issues often overlooked by the architect in a refurbishment project during the design, document preparation, and construction stages. It is also the aim of this paper to document the feedback gained from a study of refurbishment projects. A study focusing on the seven refurbishment projects was carried out in Saudi Arabia. The purpose of the study was to obtain feedback through personal interviews and in-depth discussions with the architects and the contractors of the selected projects.

\section{REFURBISHMENT PROJECTS}

Refurbishment is a generic term including rehabilitation, modernization, renovation, alterations, improvements, additions, repairs, renewals, retrofitting; the term does not include domestic maintenance work such as cleaning and emergency maintenance [12]. Refurbishment projects can be categorized based on the terms (work scope) mentioned earlier. Refurbishment projects refer to such works as improvement, adaptation, upgrading, conversion, retrofit, and repair which are carried out on existing buildings for a variety of reasons [13].

It is obvious that the various reasons for refurbishment projects have a greater or lesser degree of importance to the buildings' different interest groups. The owner expects the building to be an investment. Users are concerned about the operation of buildings, society anticipates that the buildings will at least indirectly promote the welfare of its members as well as be environmentally friendly.

A refurbishment project may be initiated suddenly because profound damage has occurred, or its initiation may be planned in advance for a chosen time according to the expected rate of deterioration [14]. The damage based refurbishment is most obviously due to the properties of the building (especially durability features). The other route to refurbishment is via changes in the use and the user of the building with normal wear and tear of the building itself. The theory of economy considers rational the project that maximizes economic utility. One may endeavor to do this directly through attempting to increase profit, or indirectly through minimizing expenditures in order to add profit potential (cost-reduction expenditure) [14]. A refurbishment initiated without building deterioration on the basis of subjective valuations only can be seen as a counterpart of failure in building. A marginal factor anticipated for initiation of refurbishment projects is a change of circumstances.

According to the above literature review, the reasons for demand of various refurbishment projects can be classified as failure in building: corrective refurbishment, change in use: space altering refurbishment, optimization of economical factors: optimizing refurbishment, subjective features: pleasure refurbishment, and change of circumstances: opportunity refurbishment.

In this paper refurbishment projects are seen as the projects that were subjected to a catastrophe during their service life: fire, earthquake, terror acts, etc. Therefore the projects fall in the class of corrective refurbishment as mentioned above. Rehabilitation and retrofitting were the work scopes for these refurbishment projects.

\section{RATIONALE FOR THE STUDY AND METHODOLOGY}

The variety to be found in types of refurbishment projects and types of contractors makes it impossible to lay down strict rules [10]. It is possible, however, to group problems frequently encountered and to suggest guidelines that if followed, will mitigate their impact on the time and cost of refurbishment projects [14]. The objectives of this paper are to present the sources of the problems in refurbishment 
work that cause delays and escalate costs, and to propose guidelines to resolve these problems. It addresses issues often overlooked by the architect in a refurbishment project during the design, document preparation, and construction stages. There are no significant research studies on refurbishment projects in eastern province of Saudi Arabia [15]. A study encompassing seven refurbishment projects was carried out in Eastern province of Saudi Arabia. The purpose of the case study of the selected projects was to obtain feedback through personal interviews and in-depth discussions with the architects and the contractors of the selected projects. The feedback was based on the participants' experience they gained from the selected projects. A brief description of the seven refurbishment projects is included in the following section, however, the documentation of the refurbished projects was not considered as a part of the research scope. This is because the objectives of the study were to present the sources of the problems in refurbishment projects that may cause delays and escalate cost and to propose guidelines to resolve these problems.

This paper deals with projects that were subjected to a catastrophe during their operating life: fire, earthquake, terror acts, etc. Refurbishing projects on historic buildings are not common in Saudi Arabia, and were not considered here. Historic methods of construction used in the original buildings create a compatibility problem with modern materials and construction techniques [16]. There was only one historic building identified in the eastern province of Saudi Arabia, however, the building was preserved by the local government in the existing condition at the original site location. The refurbishing projects on historic buildings are not common and are not implemented in the past in the eastern province of Saudi Arabia. As mentioned by Al-Ghamdi [15] the historic buildings were mostly in the remote areas of the Kingdom of Saudi Arabia, therefore very few old castles and mud houses were retained by the government. In the eastern province of Saudi Arabia, there is only one historic castle in the vicinity of Al-Hassa that was preserved by the local government [15]. Therefore the historic buildings were not considered in this research. A brief description of the seven refurbishment projects is included in the following section.

\section{REFURBISHMENT PROJECTS IN EASTERN PROVINCE OF SAUDI ARABIA}

In this study refurbishment is seen an option at the end of the service life of a building. The end of service life occurs when the building fails to perform as required in its use. The seven refurbishment projects selected for this research study were located in eastern province of Saudi Arabia. The architects and the contractors, who were involved in these projects, were interviewed to acquire in-depth knowledge about the sources of the problems in refurbishment projects that may cause delays and escalate costs. Brief descriptions about the selected projects are given below.
- Al-Khudri commercial building, a refurbishment project, was subjected to a catastrophe during its service life. The building is located at Prince Hilal Road in AlKhobar. The project was a corrective refurbishment type; it was refurbished/restored for the original users of the building prior to the fire incident. The scope of work for the architect and the contractor was to revitalize the lower floors and restore the floors above $12^{\text {th }}$ floor. Total floors of the building were 19. The project total cost was over 10 millions Saudi Riyals.

- Al-Hussaini residential tower is located on the corniche road in Dammam. The building was subjected to fire that damaged its structure and finishes. The scope of work for the architect and the contractor was to restore the building for its original users. The project total cost was approximately 8 millions Saudi Riyals.

- KB office tower, Gulf corporation office, and Al-Hassa commercial officetower are located in Al-Khobar, Dammam and Al-Hassa respectively. All these three buildings were subjected to fire that affected the buildings severely. The scope of the work for the architects and the contractors were to restore the buildings. This is because all these buildings were considered important landmarks in their respective areas. The total project costs for KB office tower, Gulf corporation office and Al-Hassa commercial office tower were 12 millions, 10 millions and 9millions Saudi riyals respectively.

- General industries regional headquarter and AlMuhawis commercial tower are located in Al-Hassa. Both these building were subjected to earthquake that impact the building very severely. This was because both these building were adjacent to each other. The scope of work for the architect and the contractor for General industries regional headquarter, was to demolish $80 \%$ of the building structure and redesign the part with new additions to structure and spaces in the building. The cost of the project was 8.5 millions Saudi riyals. The scope of work for the architect and the contractor for Al-Muhawis commercial tower was to demolish $50 \%$ of the building structure and restore the building for its original users. The restoration of this building was deemed because of the popularity of the building as major landmark in its vicinity. The cost of the project was 9 millions Saudi riyals.

The abovementioned refurbishment projects were selected for this study. The architects and the contractors who were involved in these projects were interviewed to acquire indepth knowledge about the sources of the problems in these projects.

There can be numerous sources of problems in construction projects that cause delays and escalate costs. Many previous researches indicated these sources depending on the type of construction projects, for instance, design discrepancies, ambiguity in design, variation orders, change in specifications in construction phase, lack of human resources for design firm, non- 
availability of materials and technology, insufficient working drawing details, design errors, time limitations in design phase, and weather conditions, etc. [11][16] [17][18][19][20]. However, there was no significant research study on the refurbishment projects carried out in eastern province of Saudi Arabia. The common problems in refurbishment projects are discussed in the following section.

\section{COMMON BARRIERS IN REFURBISHMENT PROJECTS}

The variety to be found in types of refurbishment projects and types of contractors makes it impossible to lay down strict rules [10]. It is possible, however, to group problems frequently encountered and to suggest guidelines that if followed, will mitigate their impact on the time and cost of refurbishment projects. This paper deals with projects that were subjected to a catastrophe during their operating life: fire, earthquake, terror acts, etc. Refurbishing projects on historic buildings are not common in Saudi Arabia, and were not considered here. Historic methods of construction used in the original buildings create a compatibility problem with modern materials and construction techniques [16]. The sources of barriers in refurbishment work can be categorized depending on the stage of work involved. These stages of project are design stage and construction stage. The sources of problems during the design stage are discussed below.

\subsection{Design Stage}

A construction project traditionally involves two major professionals in the construction industry. These two professionals are the architect and the contractor. The construction industry is very fulfilling business. Most of architects and engineers in the design profession enjoy the creative stage of a new project and following the project to the completion of construction [13]. However, they may be less enthusiastic when involved in a refurbishment project because of the constraints put on their creativity, since they have to follow the footprint of the original building with little room for modification [8]. This creates an inauspicious start to the design process that is reflected in the actions taken at this stage by the architect and/or the owner. Some of these actions are discussed below with some details and proposed remedial measures.

\subsubsection{Degradation of undamaged materials over time}

The architect, with some influence from the building owner, determines the scope of refurbishment work based on the building conditions seen at the inception of the refurbishment work [19]. Little thought is given to the fact that further deterioration of the building may occur during the time between this initial site survey and the actual start of the construction contract. This period may extend for years due to financial reasons or delays in design [10].

Existing mechanical equipment, such as pumps, chillers, cooling towers, and boilers, may suffer heavy degradation by corrosion if left out of operation for long time. Corrosion may damage the internal parts that were in contact with water. Construction equipments affected by corrosion was very much expected in Saudi Arabian construction industry, due to the severe weather conditions [16]. Pipes and valves for chilled water and domestic water supply may suffer from pitting corrosion, resulting in reduction in internal diameter so that they are unsuitable.

Electrical connections are usually more durable and can survive being out of operation for a longer period [14]. However, circuit breakers and panel boards may suffer damage when exposed to environmental attacks such as rain and dust, and are vulnerable to theft and vandalism. Similarly, architectural finishes, such as gypsum board used in lightweight partitions and false ceilings, may be damaged due to weathering.

Aluminum sections used in curtain walls, doors, and windows may suffer discoloration due to dust accumulation and humidity on the anodized layer when left unattended for years [14]. Fibrous types of fire protection applied to steel sections lose their properties and start to peel off if exposed for a long time to the external environment, rendering them unsuitable for use.

These elements may be of acceptable quality immediately after the accident. Two or three years later, at the start of the refurbishment work, they may be in poor condition and it may be necessary to replace them. If not included in the contract scope, this work will need to be addressed by variation orders during the construction phase, where the impact of the variation is more severe than in the design phase [18]. This may create an unpleasant situation for the project owner and be used by the contractor to cover his own delays. It is important during the site survey (conducted before defining the scope of the design services) to consider the possible degradation of materials over time. It is far better to include the replacement of those materials in the scope of the contract rather than having to issue variation orders on short notice during construction [18]. Replacing some of the elements at a late stage would be out of sequence for the ongoing work and could cause disruption to the progress on site.

\subsubsection{Formidable variations to original structure}

In refurbishment work, the owner often learns from the shortcomings encountered during the service life of the original building. Even if his disclosed intention is to get the facility back in operation as soon as possible, the owner may be tempted to request some modifications during the course of the design works. If not confined, these modifications may keep snowballing, with serious results [21]. This is possible because the owner and the architect may underestimate the impact of a number of minor variations on the overall project. To minimize these variations, the architect should interview the owner indepth about the design at the conceptual stage to discover 
all his intentions [20]. Incomplete information at an early stage was found to complicate the design and to be a cause of abortive work [18].

Changes to an existing structure may have a serious impact on building system [6]. For example, the addition of a floor or modification to the loading pattern may increase loads on supporting elements. The structural engineer would normally check existing elements against additional loads. If found inadequate, the designer adds strength to those elements to counter the additional load. Installing reinforced concrete jackets to columns and footings is a sensitive operation, difficult to execute, and dangerous if not approached carefully. Furthermore, the design concepts of the jackets are not well understood because there is a lack of certainty about how the jacket will function in conjunction with the old element [10].

Clancy [22] listed some specific skills and knowledge required for the structural engineer to perform such work. In general terms, the structural engineer should be able to appreciate the philosophy of the original construction, have a good pragmatic knowledge of structural theory, understand the effects of natural phenomena such as wind on buildings, understand the effects of ground movements, and have some information on historic forms of construction and behavior of materials in construction.

To perform the design for variations related to additional loads, the designer has to depend on available information about the original building: design documents and/or asbuilt drawings [23]. In many cases they may actually deceive the designer. In the case of a five star hotel, the footings for a retaining wall were shown with certain dimensions and reinforcement on the as-built drawings. However, when uncovered during the refurbishment work, they were found to have smaller dimensions, to be without reinforcement, and to be located at higher level. This meant that the jackets designed could not be placed, both because of the inadequacy in the existing footings and because they would protrude above the actual finished floor level.

To reduce the risk of such changes, the architect should not alter the loading system carried by existing structural elements; but when it is necessary, he should not overload them by more than $10-20 \%$ of their original capacity for greater loads, additional supports should be used rather than adding jackets to existing elements [10]. This will minimize the problems of incompatibility between existing conditions and as-built drawings, and enhance constructability.

\subsubsection{Salvaged materials}

Since damage may be localized, it is sensible for the architect to be expected to incorporate materials from the original building in his design [10]. From a cost-saving point of view, the project owner encourages this trend. The architect may overlook the fact that though these materials look fine and suitable for reuse during the initial survey, they will look different from new materials installed adjacent to them [11]. This may happen particularly with finishes such as aluminum profiles and marble, due to age. Colored materials suffer from fading and loss of glossiness because of exposure to ultraviolet rays [14]. Used materials, of course, should be massed in certain areas to avoid having new and old elements in one zone [24]. This reduces the likelihood of showing the contract between the two.

However, not all materials can be relocated safely without being damaged in the process. Marble tiles and fixed wooden decorations, for example, tend to break during removal and hence replacement of a larger quantity may be deemed necessary. It is better to include these in the contract scope to avoid delays and increased expenses when dealt with as variation orders later on.

\subsubsection{Conflict between responsibilities and liabilities}

To be cost effective, the owner and the architect may try to limit the contractor's scope of work to damaged areas only. At the same time, the owner wants the whole building to function properly at the completion of the work. Hence, the owner and the architect insert in the contract conditional clauses to the following effect:

- To minimize the interference of the refurbishment contractor in existing unaffected work to reduce cost.

- To maximize the responsibility of the contractor over the whole of the work.

These are contradictory, and create a conflict between the owner and the contractor. The later will not accept liability for the old materials unless they have been tested and proved suitable. This is difficult to asses fairly, and in most cases a wise contractor recommends removing old materials to reduce his risks and increase his profits [13]. On the other hand, the owner may resist yielding to these recommendations and insist on receiving concrete evidence of the unsuitability of the materials before agreeing to replace them. Both parties maintain their position to a point when one eventually yields to the other. In most cases, the owner is forced to yield to the contractor's demands either to save time or just to resolve the problem [25][26]. Such disputes may develop into a claim by either party. In this case, the chances are that the owner will lose, due to the rule that in case of ambiguity, the courts decide against the author of a contract [27].

There is no simple solution to this problem. Increasing the bidding period to give bidders time to examine existing materials and conduct a thorough appraisal of the building and its components at the start of the contract will help to resolve any resulting disputes [18]. The contractor has to be reasonable in submitting requests to replace existing materials, and should base these requests on solid technical evidence. The owner and architect should be reasonable in assessing these requests. 


\subsubsection{Missing design information}

Design details are the graphical forms of communication between the designer and the contractor [20]. To convey a complete concept of the project design, the drawings must be clear and concise. Insufficient design information can result in misinterpretation of the actual requirement of a project [1][26]. Thorough reviewing of design details can minimize variations caused by inadequacy of design details. Normally, in the initial stages, the conceptual design is done rapidly, using little information other than the owner's brief, the site constraints, and the architect's own experience. In nearly all case studies done by the researcher, the initial concept formed the general basis of the final design. Hence the initial information available at the start of the design is vital. The case studies feedback shows that for refurbishment projects, there is always lack of information at this stage due to missing design documents and construction records. As-built drawings, if available, do not necessarily conform accurately to actual conditions, either because of inaccuracy in their preparation or subsequent changes made by the project owner that are not reflected on the drawings. These conditions are particularly true in Saudi Arabia, where many large projects have been designed and built by international architectural firms and contractors not stationed in the area [18]. Retrieving information from these sources years after the completion of the original construction stage is difficult, to say the least.

Site surveys may be the only source for such information as geometry and leveling. However, for certain services, such as electrical works, site surveys may not yield any useful information. Unless as-built drawings are found and are accurate, the electrical designer has to spend days on the site, tracing each circuit [13]. It helps to have among the design team members who are experienced in the construction methods used in the project and can provide missing information about materials and techniques used.

\subsubsection{Illogical imposed conditions}

Certain building elements cannot be replaced by new ones with exactly the same dimensions and weights to fit the existing space and/or supporting structures. Expecting the contractor to resolve these issues will create problems [28]. For example, in a case study of refurbishment project studied by the researcher, the structure was burnt and the replacement of the elevators was necessary. The architect inserted a condition in the specifications that the contractor was to use the existing steel cages to support the new equipment. The contractor was to survey the cages and ensure their adequacy before finalizing the selection of the new elevators. Any necessary modifications required as a result of this selection were to be borne entirely by the contractor. This is illogical for several reasons.
- During the tendering stage, the bidders do not have the time to visit or the access to the site to check the adequacy of the existing elements.

- Continuous changes in equipment design render it impossible to find equipment with the same dimensions and weights to fit exactly in the place of old ones.

The architect must consider these facts and be prepared to modify the design of affected elements to suit newly selected equipment. The cost of such design and construction work should be treated as a variation order to be borne by the owner. It may, however, be argued that no time implications should be considered for such a variation, for the contractor should allow for such work in his time program [21]. This can be assessed by the architect based on the size of the work and the resulting delays, if any.

\subsubsection{Selecting contract type}

Contract documents are the main source of information for any project. Conflict between contract documents can result in misinterpretation of the actual requirement of a project [18]. To convey complete project scope for participants, the contract documents must be clear and concise. Insufficient details in contract documents may adversely affect the project, leading to rework and delay in project completion [18][26].

Due to the high degree of uncertainty in refurbishment work, it is advisable to adopt a re-measured type of contract, where the contractor quotes unit rates of work based on approximate quantities calculated by the architect and included in the tender documents. In case the quantities vary due to site conditions, these unit rates will be used [10]. Normally those rates will be subject to modification if the total value of changes exceeds a certain limit given in the contract. Typically $10-15 \%$ is the limit used for new construction projects. For refurbishment work, it may be reasonable to increase this limit to $25-35 \%$ [10]. This is fair to both parties of the contract. The main drawback of a re-measured contract is that it is openended. The owner may not know the total cost of the project until completion.

Better still, a cost-plus contract may be the most suitable to reduce risks on either the owner or the contractor. However, such types of contracts need a high degree of control and hence, are not usually welcomed by owners of small firms or owners who do not have the sufficient staff to administer such contracts [29].

Some owners prefer to use a lump sum form of contract so as to have a figure that is not necessarily accurate at the very beginning of the work [29]. This is especially true of governmental authorities in Saudi Arabia. The reason for this preference is purely financial, since it is easier under local budgeting system to assign a budget for a project if the initial cost of the contract quoted by a contractor is known, rather than having a cost estimate from the 
architect or other sources [1]. Furthermore, many owners think that by having lump sum contracts, they have passed the project risks to the contractor [29]. They couldn't be more wrong.

Having a lump sum contract may well be very dangerous for the contractor due to the high risk involved. However, if forced to accept such a contract, the contractor shall either increase his margin to protect his interests or cut corners during the construction stage by using inferior materials to minimize his losses [13]. Furthermore, he may employ all his skills to establish that all instruction issued to him by the architect have additional implications on cost and time [18]. As a result, the project cost may escalate because of the high risk included in he contractor's price. It may suffer delays, face litigation due to claims from the contractor requesting additional cost and time, and counter claims from owner against the contractor due to damages incurred. In short, the owner's intention to pass risks to the contractor backfires on him and the project as a whole suffers.

To assist the owner in establishing total costs, the architect can provide a fair price estimate based on the most up-todate unit rates and add $40-50 \%$ to cover unforeseen factors. The more accurate the initial survey done by the architect, the lower this margin needs to be [19]. In short, the architect should use all his wits to convince the owner not to have a lump sum contract to avoid unnecessary paperwork and legal claims.

\subsection{Construction Stage}

In a new building project, the construction work starts with a clear site. For a refurbishment project, the work starts with an existing building. It is to be expected, therefore, that the sequence of work in refurbishment projects is different from new buildings. Those involved in such projects must be prepared to adopt necessary variations in their methods to accommodate these differences. Some common shortcomings that arise in refurbishment work during the construction stage are discussed below.

\subsubsection{Improper site survey}

During the early stages of a refurbishment project, the contractor surveys the site to identify the condition of existing equipment and materials. The contractor is accompanied by the resident site staff from the architectural firm [6]. This site survey is of the utmost importance since it will determine the actual scope of work for areas not well-defined in the documents. If neglected, the owner and the contractor may enter into dispute about whether damage seen during the course of the work occurred before or after the contractor entered the site [13]. Recording existing conditions with photographs or videotape may prove beneficial. During the survey the architect will categorize the materials on site: 1) those to be removed and replaced by new, 2) those to be removed and repaired for reuse, and 3) those to be maintained and protected for reuse [8].

A plan resulting from this survey will be prepared to deal with materials in the first category. Normally the contract will state the ownership of these materials. Materials in the second category should be well-documented by the architect on behalf of the owner. The contractor through his specialized subcontractors should take good care of these materials [3]. The contractor tests and maintains those materials in the third category to be ready for reuse, storing them safely to ensure their reinstallation with minimum losses. The survey has to be done as thoroughly as possible to avoid overlooking any defective elements [18]. The contract should ensure that the contractor acts promptly in this regard. If this is not done, defective materials may be discovered at a late stage of the project, making last minute variation orders necessary and adversely impacting the scheduled completion [20].

\subsubsection{Concurrent operation by owners}

Most refurbishment work is usually carried out to partially damaged buildings. If other parts are in operating condition, owner may be tempted to minimize the shutdown period of those areas [19]. This means the refurbishment contractor does not have full possession of the site. Tenants or staff may be sharing parts of the building with the contractor. Liability becomes vague for damages occurring in those areas. It is important that the construction contract informs the contractor of areas that the owner will maintain as operational and for how long [29]. It is equally important to include relationships among related activities and areas maintained in operation in the contract documents and in the schedule of works submitted by the contractor [10]. The time when total building shutdown is required should be known to all parties and in case of disagreement, should be covered contractually.

The architect needs to act impartially and if necessary, strongly, to ensure that the owner does not delay the handing over of occupied areas to the contractor at the specified time. If the owner delays this handing over, the architect should keep records of delays in case the contractor claims additional time and/or cost [13]. In this way, the architect may win the trust and respect of both parties.

\subsubsection{Selection of contractor}

Selecting a contractor who is experienced in refurbishment projects is important. Clancy [3] stressed that the selected contractor for refurbishment work plays an essential role as a member of the construction team, even more so than with new buildings. An experienced contractor may assist the team with his knowledge about contemporary techniques and materials, and may identify areas of variation at an early stage of the project, to everyone's benefit [18]. Such a contractor may be expensive, but in 
the long run will be more economical than a contractor with little or no experience, which may cost the project extended delays. Prequalification of contractors invited for bidding is necessary.

Assure the bidders that the contract will be signed with the lowest bidder without further negotiations for discounts. This not only creates a real sense of competition, but it is also ethical [10]. Owners should be discouraged from trying to reduce the price any further. The bidding period must be long enough for the bidders to visit the site and have sufficient time to inspect it. They may notice things the architect overlooked [28]. Careful attention should be paid to the bidder's queries to the architect during this period. Holding a pre-bid meeting to present the project to the bidders and to clear up any ambiguity resulting from the tender documents is highly recommended [25]. The architect should respond in writing to any queries well before the bid closing date, to give contractors time to adjust their price [6]. A wise architect records accurately the queries raised during the pre-bid and received by mail and revises his design if necessary [10]. These actions may eventually serve the project and the owner. The owner gets the lowest realistic price with fewest hassles during the construction phase.

\subsubsection{Escalated costs and delays during refurbishment}

Variation orders for refurbishment work generally exceed the expected limits of $10-20 \%$ experienced in new buildings [21]. The owner may start the project with inadequate project objectives. Due to inadequate project objectives, the designer would not be able to develop a comprehensive design, which leads to numerous variations during the project construction phase [20]. In certain cases it would have been cheaper not to refurbish but to rebuild. Unfortunately, this information usually becomes available only after the event. In other words, no one could have reached this conclusion at the beginning of the project. Much is dependent on the initial survey performed by the architect before the design phase. The more comprehensive the survey, the more certain the reply of the architect to the question.

Since most refurbishment projects are profit-generating buildings, time is of the essence [19]. As the number of variation orders increases, the time schedule is repeatedly extended [21]. The profit loss may escalate and frustration may increase. If time control is important for all construction projects these days, it is essential to refurbishment projects [13]. An experienced planner on site with the architectural team is required to handle contract administration. The contract documents should insist that planning engineers with suitable experience should be included among the contractor's site staff as well, to update the time program periodically. Having a planning unit at the contractor's head office to perform this duty is not sufficient [10]. Decisions should be made on the spot by the contractor's agent on site, supported by his planner.
In refurbishment projects the architect's planner plays an important role in decision making. Planner should review any required variations initiated by the owner, architect, or others and determine their implications before issuing the variations to the contractor [19]. Though this should be practiced in all projects, it becomes more critical in refurbishment projects, which suffer the most because of the number of variations that may be involved. Many of the variations ordered in refurbishment work by the owner would be cancelled had the architect informed the owner, in good time, of their implications.

Planners should be aware that the productivity rates for activities in refurbishment projects are usually lower then newly built projects. Thomas and Napolitan [30] reported that in newly built projects the productivity rates for variation orders issued for finished work was low, because the work area was congested and the work performed was out of sequence. Productivity rates in refurbishment work are expected to be very much like the rates in newly constructed buildings undergoing late variations.

\subsubsection{Underpayment for architect's services}

In newly constructed facilities, cost estimation for the project can be fairly accurate. The architect's fees can be estimated accurately as a percentage of the total cost. This practice is well-defined and the rules are sometimes dictated by the local regulations in Saudi Arabia [1].

This is not the case for refurbishment work. It was revealed from the case studies of refurbishment projects in Saudi Arabia that the design and construction contract administration fees for the architect performing the refurbishment contract were normally underestimated. They were calculated based on approximate cost estimates done in the initial stages of the design, before the owner's ambitious plans for improvements were uncovered. In one particular case, the estimated project cost was tripled by the time of tendering as compared to the initial cost estimate at the design contract. This was further increased by $50 \%$ during the construction stage, due to unforeseen variations [1].

Design services do not end at the beginning of the construction phase, as normally is the case in newly constructed facilities [13]. They continue far beyond this point to accommodate unforeseen conditions during construction. Variations due to increased scope require design and coordination work throughout most of the construction phase [3]. The design team is frequently consulted for variations observed on site between existing conditions and those shown on the drawings.

Consequently, conflicts between the project owner and the architect are bound to occur and may have a negative impact on the progress of the work [16]. To avoid these problems, the owners should be reasonable in responding to the architect's requests for additional design fees, and 
the architect, on the other hand, should minimize variations to the team involved in the projects. A major problem may occur if the members of the design team are involved in other projects or have left the architectural firm [11]. A serious misjudgment may take place when new member of the team is introduced to a problem that has a background unknown to the available team [10]. The architect should keep records of all correspondence and decisions made during the design stage so that newcomers to the team can access background information when needed.

\section{CONCLUDING REMARKS}

Refurbishment projects are unique in their nature in many ways and should be approached cautiously by the architect commissioned to the design them. There was no significant research carried out considering the refurbishment projects in eastern province of Saudi Arabia. This study presents the twelve most important sources of barriers in management of refurbishment projects revealed through in-depth interviews with the project architects and the contractors of the seven refurbishment projects selected in eastern province of Saudi Arabia. The problems revealed in this study, indicate that degradation of undamaged materials over time, formidable variations to original structure, salvaged materials, conflict between responsibilities and liabilities, missing design information, illogical imposed conditions, selecting contract types, improper site survey, concurrent operation by owners, selection of contractor, escalated costs and delays during refurbishment, and underpayment for architect's services were considered as most important sources of problems in refurbishment projects. In addition, a lack of experience on the part of the architect is also considered as the major source of inconsistencies. Numerous common problems could be avoided if a more thorough survey was conducted of the existing building at the initial design stage. Teamwork and sincere efforts from all parties go a long way to resolve such problems. The more thorough the initial appraisal made by the architect, the fewer problems seen later on. Designers involved in refurbishment projects have to realize that though their creativity and design talents are not used in these projects to create new design, they will have put them to good use if their projects succeed in meeting the target cost and time for reopening.

Finally, as this study is based on the interview sessions with the architects and the contractors, who were involved in the refurbishment projects in eastern province of Saudi Arabia, further works can be extended to survey all the consultants and the contractors who have carried out refurbishment projects in other provinces of Saudi Arabia.

\section{REFERENCES}

[1] Arain, F.M. (2002) Design-Construction Interface Dissonances, unpublished MS Thesis, King Fahd
University of Petroleum and Minerals, Dhahran, Saudi Arabia.

[2] Wang, Y. (2000) Coordination issues in Chinese large building projects, Journal of Management in Engineering, 16(6), pp. 54-61.

[3] Clancy, B.P. (1995) New buildings from old: some views on refurbishment projects, The Structural Engineer, 73(20), pp.341-346.

[4] Hamad, B.S. (1993) Evaluation and repair of wardamaged concrete structures in Beirut, Concrete International, 15(3), pp. 47-51.

[5] Hamid, A.A.; Fereig, S.M.; Al-Khaiat, H. and Darwish, A.H. (1993) Assessment and repair of wardamaged concrete buildings in Kuwait city, Concrete international, 15(3), pp. 52-54.

[6] Clough, R.H. and Sears, G.A. (1994) Construction Contracting. ( $6^{\text {th }}$ edition) John Wiley \& Sons Inc., New York.

[7] Mendelsohn, R. (1997) The constructability review process: A constructor's perspective, Journal of Management in Engineering, 13(3), pp.17-19.

[8] Chappell, D. and Willis, A. (1996) The Architect in Practice $\left(8^{\text {th }}\right.$ edition) Blackwell Science Ltd, Malden, MA. USA.

[9] Fredrickson, K. (1998) Design guidelines for designbuild projects, Journal of Management in Engineering, 14(1), pp. 77-80.

[10]Daoud, O.E. (1997) The engineer's role in rehabilitation work, Journal of Management in Engineering, 13(1), pp.1-5.

[11] Assaf, S.A., Al-Hammad, A.M. and Al-Shihah, M. (1996) Effects of faulty design and construction on building maintenance, Journal of Performance of Constructed Facilities, 10(4), pp. 171-174.

[12]Quah, L.K. (1988) an evaluation of the risks in estimating and tendering for refurbishment works, unpublished $\mathrm{PhD}$ Thesis, Department of Building, Heriot-Watt University, UK.

[13]Egbu, C.O.; Young, B.A. and Torrance, V.B. (1998) Planning and controls processes and techniques for refurbishment management, Construction Management and Economics, 16(3), pp.315-326.

[14] Aikivuori, A. (1996) Periods and demand for private sector housing refurbishment, Construction Management and Economics, 14(1), pp.3-13. 
[15] Al-Ghamdi, A. (1999) An overview of construction industry in the Kingdom of Saudi Arabia, unpublished MS Thesis, King Fahd University of Petroleum and Minerals, Dhahran, Saudi Arabia.

[16] Assaf, S.A., Al-Khalil, M. and Al-Hazmi, M. (1995) Causes of delays in large building construction projects, Journal of Construction Engineering and Management, ASCE, 11(2), pp. 45-50.

[17] Arain, F.M. and Assaf, S. (2003) Project design and construction interface dissonances, Jounral of Research in Architecture and Planning, (2), pp.69-80.

[18] Arain, F.M.; Assaf, A.A. and Low, S.P. (2004) Causes of discrepancies between design and construction, Architectural Science Review, 47(3), pp. 237-249.

[19]Fisk, E. R. (1997) Construction Project Administration. ( $5^{\text {th }}$ edition) Prentice Hall, N.J.

[20] O’Brien, J.J. (1998) Construction Change Orders. McGraw Hill, New York.

[21] CII (1990) The Impact of changes on Construction Cost and Schedule, Publication 6-10, Construction Industry Institute, University of Texas, TX.

[22]Clancy, B.P. (1994) The role of the structural engineer in maintaining the built environment, The Structural Engineer, 72(21), pp.365-367.

[23] Al-Hammad, A.M. and Assaf, S.A. (1992) DesignConstruction interface problems in Saudi Arabia, Journal of Building Research and Information, 20(1), pp. 60-63.

[24] Cox, S. and Hamilton, A. (1995) Architect's Job Book. ( $6^{\text {th }}$ Edition) RIBA Publications, Royal Institute of British Architects, UK.

[25] Al-Hammad, A.M. (2000) Common interface problems among various construction parties, Journal of Performance of Constructed Facilities, 14(2), pp. 71-74.

[26] Puddicombe, M.S. (1997) Designer and Contractors: Impediments to Integration, Journal of Construction Engineering and Management, 123(3), pp. 245-252.

[27] Jergeas, F.J. and Hartman, F.T. (1994) Contractor's construction claims avoidance, Journal of Construction Engineering and Management, 120(3), pp. 533-560.
[28] Adrian, J.J. (1983) Building Construction Handbook, Reston Publication Co., Virginia.

[29] CII (1986) Impact of Various Construction Contract Types and Clauses on Project Performance, Publication 5-1, Construction Industry Institute, University of Texas at Austin, TX.

[30] Thomas, H.R. and Napolitan, C.L. (1995) Quantitative effects of construction changes on labor productivity, Journal of Construction Engineering and Management, 121(3), pp.290-296.

\section{APPENDIX 1}

\section{Definitions}

$\underline{\text { Refurbishment }}$

Refurbishment is a generic term including rehabilitation, modernization, renovations, alterations, improvements, additions, repairs, renewals, retrofitting; the term does not include domestic maintenance work such as cleaning and emergency maintenance [2].

\section{$\underline{\text { Service life }}$}

Service life (of a building material or component): the period of time after installation during which all essential properties meet or exceed minimum acceptable values, when routinely maintained [28].

\section{$\underline{\text { Performance }}$}

Performance of materials: for a defined requirement, the performance of a material is its response to the action of extrinsic factors. The nature of the response is due to the intrinsic properties of the material [20].

\section{Performance requirement}

User requirement expressed in terms of the performance of a product [16]. A qualitative statement of the performance required from a building component or material [20].

\section{$\underline{\text { Degradation mechanism }}$}

The sequence of chemical, mechanical or physical changes that lead to detrimental changes in one or more properties of a building material or component, when exposed to one or more degradation factors [2].

\section{$\underline{\text { Deterioration }}$}

Deterioration is the process of becoming impaired in quality or value [20]. 